\title{
Chemical Design, Synthesis and Bio-efficacy Screening of New Growth Inhibitors of Spodoptera littoralis (Boisd.)
}

\author{
Mohamed A Gad ${ }^{1 *}$, Elwassimy MM1ㅜ, Safwat A Aref ${ }^{1}$ and Antar A Abdelhamid ${ }^{2}$ \\ ${ }^{1}$ Research Institute of plant protection, Agriculture Research Center, Egypt \\ ${ }^{2}$ Department of Chemistry, Faculty of Science, sohag University, Egypt
}

ISSN : 2688-8394

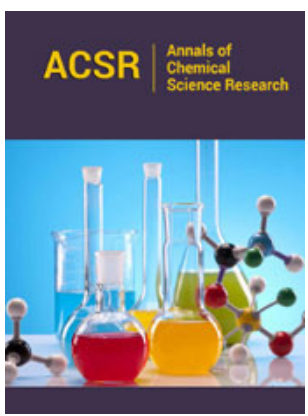

*Corresponding author: Mohamed A Gad, Research Institute of plant protection, Agriculture Research Center, Egypt

Submission: 制 October 09, 2019

Published: 此 October 22, 2019

Volume 1 - Issue 4

How to cite this article: Mohamed A G, Elwassimy M, Safwat A A, Antar A A. Chemical Design, Synthesis and Bio-efficacy Screening of New Growth Inhibitors of Spodoptera littoralis (Boisd.). Ann Chem SciRes.1(4).ACSR.000520.2019. DOI: 10.31031/ACSR.2019.01.000520

Copyright@ Mohamed A Gad, This article is distributed under the terms of the Creative Commons Attribution 4.0 International License, which permits unrestricted use and redistribution provided that the original author and source are credited.

\begin{abstract}
The present work aimed to find new growth inhibitors agents spodoptera littoralis (Boisd.), several inhibitors structurally relevant to the insect growth regulator, Fenoxycarb and the naturally transpiring juvenile hormone of insects were chemically designed, prepared and evaluated as anti-proliferative agents. Epihalohydrins derivatives have been synthesized and their agricultural bio-efficacy as insecticides against spodoptera littoralis (Boisd.). Insecticidal bio-efficacy data showed that that some compounds are very active against spodoptera littoralis (Boisd.)
\end{abstract}

Keywords: Insecticidal bio-efficacy; Spodoptera littoralis (Boisd.); Insect growth regulator; The toxicity ratio

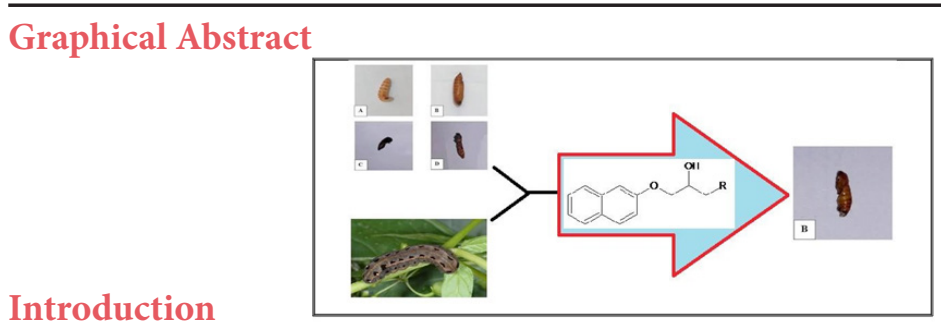

Spodoptera littoralis (Boisduval) (Lepidoptera: Noctuidae) is considered one of the key pests that cause great damage to cotton plants as well as other plants in Egypt [1,2] larvae of this insect can feed on about ninety economically, monetarily and significant plant pertinence to forty families. The achieved control is not successful, when using synthetic insecticides [3] and some biorational agents for example Bacillus thuringiens is Berliner to resist the pest, because of the insect's high ability to develop resistance toward most of traditional components [4]. Therefore, we need novel compounds that are efficient against this insect, safe to human and ecological well-disposed $[5,6]$. The substitutional control techniques that show presage as a potential tactic in S. littoralis the executive's projects is the utilization of biorational control operators for example synthetic insect growth regulators and those dependent on normally materials [7]. Insect growth regulators are development controllers are ventured to be more secure for useful living beings than regular mixes, and they have been effectively utilized in IPM programs against many tree and little natural product $[8,9]$. There is a need for different insecticides having different modes of action Juvenile hormones analogues [10-13] sesquiterpenoid moieties arranged and discharged by the corpora allata, are significant insect hormones that standardize a bulky diversity of processes during postembryonic growth and adult reproduction in insects [14]. Juvenile hormone analogues display powerful creepy crawly adolescent hormone-mirror action, and consequently cause genuine aggravations in the advancement, multiplication, and conduct of a wide scope of bug [15-16]. This carbamate is utilized for pests' control in farming, ranger service, and put away items, and is additionally utilized as a general wellbeing bug-spray Juvenile hormone analogue is recorded for control of caterpillars, and scales in Europe, and for flame ants in the U.S. Like most IGRs, fenoxycarb has surprisingly low human toxic quality and is significantly more bug particular than the ordinary bug sprays [17]. The main objective of this study was to determinate the toxicity of new growth inhibitors agents against the cotton leafworm, $S$. littoralis larvae under laboratory conditions. 


\section{Results and Discussion}

The start reagent can be prepared by the reaction of 2-naphthol with epichorohydrin in presence of catalytic amount of sodium hydroxide afforded of 2-((2naphthyloxy) methyl)-oxiran1a (Figure 1-3).<smiles>O=Nc1ccc2ccc(OCC3CO3)cc2c1</smiles>

$1 a$

Figure 1: Synthesis of 2-((2naphthyloxy) methyl)-oxiran 1a

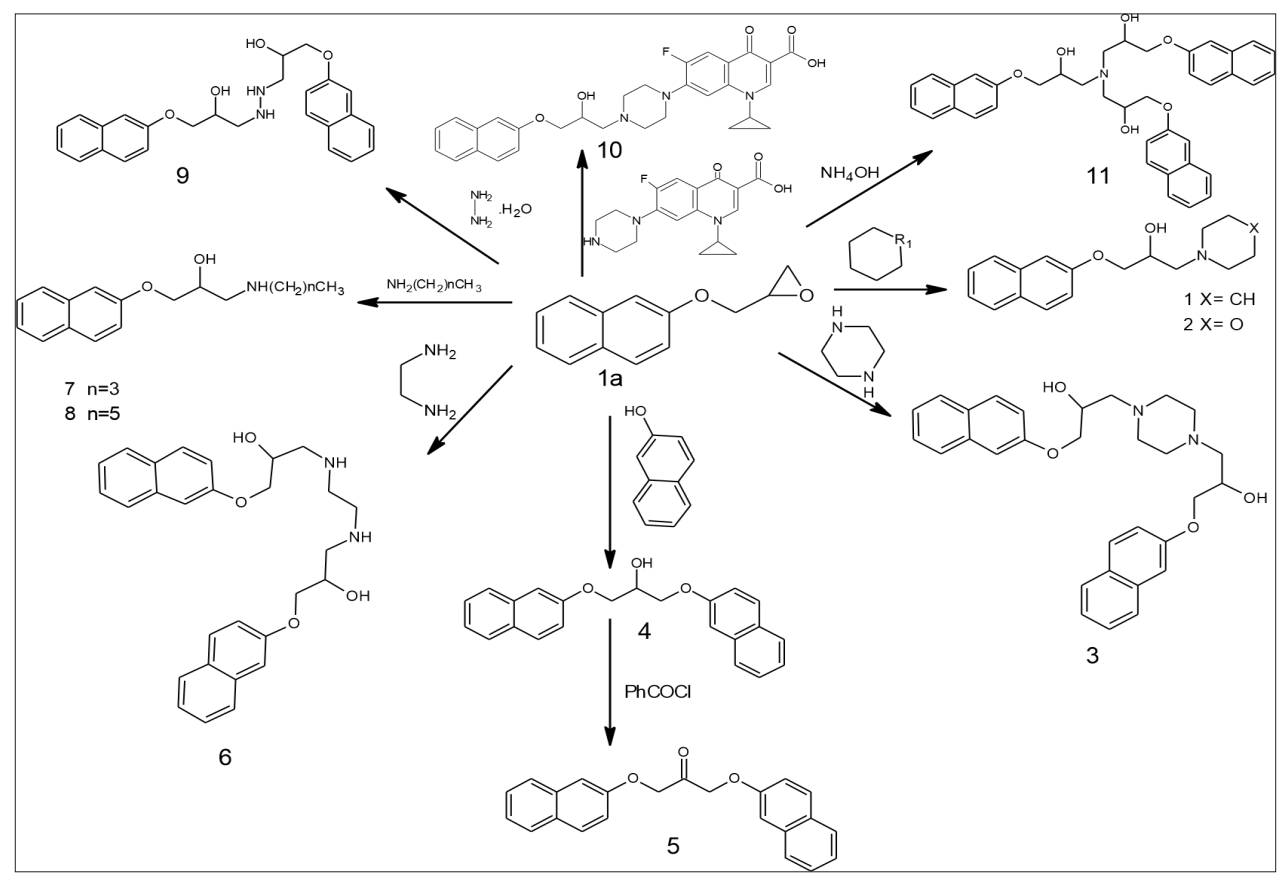

Figure 2: The nucleophilic attack of compound 1a

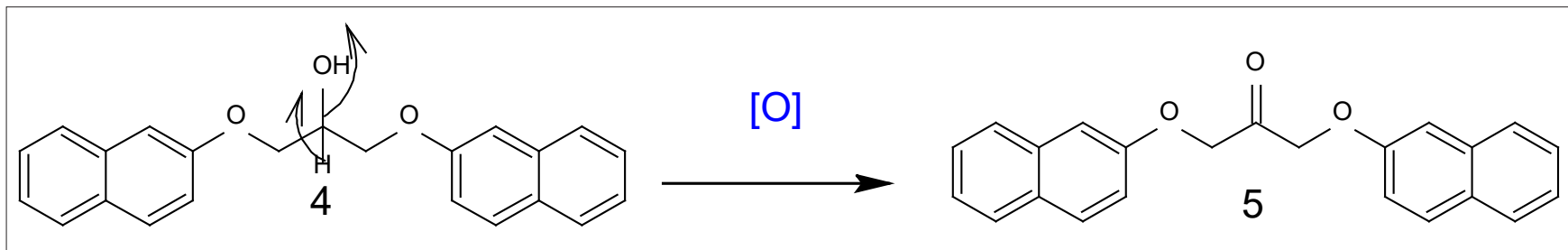

Figure 3: Oxidation of compound 4

\section{Experimental}

A Fisher-Johns apparatus was exercised to register the MP. of every synthesized compound. Infra-red and elemental analyses (C, H, N, and S) were accomplished through a Pye Unicam SP3-100 spectrophotometer utilizing the $\mathrm{KBr}$ disk manner and a Vario EL C, H, N, S analyzer, separately. A Bruker $400 \mathrm{MHz}$ spectrometer was utilized to measure DEPT 135 spectra and the $1 \mathrm{H}$ and 13C NMR spectra within the TMS as an interior standard. Chemical shifts were estimated in ppm. Reaction headway and perfection of the prepared sections were checked by thin layer chromatography. The insecticidal reference, fenoxycarb (insect growth regulators), was achieved from Sigma Aldrich (France), spodopetra littoralis (Boisd) were combined from cotton area of the exploratory farm of Agricultural research center. The insecticidal effective of the 
reported fenoxycarb juvenile hormones as active ingredient and the prepared components was screened against larvea of the spodopetra littoralis (Boisd).

Synthetic Procedure for 2-[(naphthalen-2-yloxy) methyl] oxirane(1a). According to the reported procedure, by reaction of 2-naphthol $(0.04 \mathrm{~mol})$ with epichlorohydrin $(0.12 \mathrm{~mol})$ and sodium hydroxide $25 \%$ in water was stirred in ice bath for $4 \mathrm{~h}$, compound 1a was prepared, The formed precipitate was filtered off and recrystallized from methanol in which give white powder of 1 a. Yield: 81\%; MP.92-94 ${ }^{\circ} \mathrm{C}$. IR (v) (KBr) cm $\mathrm{cm}^{-1}, 3049$ (C-H aromatic), 2913, 2880 (C-H aliphatic); 1H NMR (DMSO-d6): 86.7 (m, 7H, $\mathrm{Ar}-\mathrm{H}$ ), 4.47, 3.91, 3.41,2.77, 2.76 for (s. $1 \mathrm{H}, \mathrm{CH}$ ), respectively. Elemental analysis calculated for $\mathrm{C}_{13} \mathrm{H}_{12} \mathrm{O}_{2}$ (\%) Calcd. /found $\mathrm{C}$, 77.98/77.97; H, 6.04/6.02.

General Procedure of Synthetic 3-Cyano-4, 6-distyrylpyridine$2(1 \mathrm{H})$-thione $(1-4,611)$. A mixture of compound $1 \mathrm{a}(1 \mathrm{mmol})$, nucleophile $(3 \mathrm{mmol})$ and drops of tri ethylamine in ethanol was stirred and refluxed at ambient temperature for $5 \mathrm{~h}$ to give a precipitate which filtered off and recrystallized from 1,4-Dioxan. 1-(naphthalen-2-yloxy)-3-(piperidin-1-yl) propan-2-ol (1) Pale red crystals. Yield: 91\%; MP: $119-122^{\circ} \mathrm{C}$. IR (v) (KBr) cm${ }^{-1}: 3362(\mathrm{OH})$, 2934, 2915, 2824 (C-H aliphatic). 1H NMR (DMSO-d6): 87.19-7.89 (m, 7H Ar-H), $4.72(\mathrm{~s}, 1 \mathrm{H}, \mathrm{OH}), 4.11(\mathrm{~s}, 1 \mathrm{H}, \mathrm{CH}), 4.00$ (m, 4H, 2CH2), 1.5 (m. 10H, 5CH2).13C NMR (DMSOd6): $\delta 157.20,134.81,129.69$, $127.21,126.77,123.92,119.2,107.25,71.78,70,28,67.00,55.32$, 26.19, 24.64. Elemental analysis calculated for $\mathrm{C}_{18} \mathrm{H}_{23} \mathrm{NO}_{2}(\%)$ Calcd./found C, 75.76/75.77; H, 8.12/8.11; N, 4.91/489.

\section{1-(morpholin-4-yl)-3-(naphthalen-2-yloxy) propan-2-ol (2)}

Yellow crystals in 59\% yield, M.P112-115 ${ }^{\circ} \mathrm{C}$. IR(v) (KBr) $\mathrm{cm}^{-1}$ : $3316(\mathrm{OH}), 3273(\mathrm{NH}), 3080$ (C-H aromatic), 2989, 2879 (C-H aliphatic). 1H NMR (DMSO-d6): $87.18-7.89$ (m, 7H Ar-H), 4.72 $(\mathrm{s}, 1 \mathrm{H}, \mathrm{OH}), 4.1(\mathrm{~s}, 1 \mathrm{H}, \mathrm{CH}), 4.00(\mathrm{~s}, 4 \mathrm{H}, 2 \mathrm{CH} 2), 1.5(\mathrm{~m} .8 \mathrm{H}, 4 \mathrm{CH} 2)$. 13C NMR (DMSO-d6): $\delta 157.20,134.81,129.69,127.94,127.21$, $126.03,125.77,107.25,71.78,67.00,62.36,26.19,24.64$. Elemental analysis calculated for $\mathrm{C}_{17} \mathrm{H}_{21} \mathrm{NO}_{3}(\%)$ Calcd. /found $\mathrm{C}, 71.06 / 71.05$; H, 7.37/7.36; N, 4.87/4.86.

\section{3,3'-(piperazine-1,4-diyl) bis(1-(naphthalen-2-yloxy) propan- 2-ol) (3)}

Yellowish white powder $87 \%$ yield, MP.188- $190^{\circ} \mathrm{C}$. IR (v) (KBr) $\mathrm{cm}^{-1}: 3377$ (OH), 2925, 2815 (C-H aliphatic), 1H NMR (DMSO-d6): 7.18-7.89 (m, 14H Ar-H). 4.84 (s, 2H, OH), 4.13(s, 2H, 2CH), 4.01 (s. 8H, 2CH2), 2.3(s. 8H, 4CH $_{2}$.13C NMR (DMSO-d6): $\delta 157.16,134.78$, $129.71,127.94,126.80,123.96,107.27,71.61,67.01,61.61,54.13$. Elemental analysis calculated for C30H34N2O4 (\%) Calcd. /found C, 74.05/74.03; H, 7.04/7.02; N, 5.76/5.77.

\section{1,3-bis(naphthalen-2-yloxy) propan-2-ol (4)}

White powder $79 \%$ yield, MP. $111-113{ }^{\circ} \mathrm{C}$. IR (v) (KBr) $\mathrm{cm}^{-1}$ : 3293 (OH), 3056, 3026 (C-H aromatic), 2928, 2877 (C-H aliphatic), 1H NMR (DMSO-d6): $\delta$ 7.21-7.85 (m, 14H, Ar-H), $5.56(\mathrm{~s}, 1 \mathrm{H}$, $\mathrm{OH}), 4.42(\mathrm{~s}, 1 \mathrm{H}, \mathrm{CH}), 4.25\left(\mathrm{~s}, 4 \mathrm{H}, 2 \mathrm{CH}_{2}\right.$ ).13C NMR (DMSO-d6): $\delta$
139.20, 136.21, 133.69, 132.35, 128.85, 128.77, 125.32, 37.3, 45.25. Elemental analysis calculated for $\mathrm{C}_{23} \mathrm{H}_{20} \mathrm{O}_{3}$ (\%) Calcd. /found C, 80.21/80.19; H, 5.8/5.7.

\section{Synthetic procedure for 1,3-bis(naphthalen-2-yloxy) propan- 2-one (5)}

Solution of compound 4 (1g, $0.0029 \mathrm{mmole})$ from ethanol absolute $(10 \mathrm{ml})$ added to sodium ethoxide solution (0.06 gram, $0.0025 \mathrm{mmole}$ ) and benzoyl chloride (0.49gram, $0.0025 \mathrm{mmole}$ ) then refluxed for 5 hours. The product was formed are filtered off and recrystallized from methanol to afford compounds 5. Yellowish white in 51\% yield, MP. $162-164{ }^{\circ} \mathrm{C}$. IR (v) (KBr) cm ${ }^{-1}: 2897$ (C-H aliphatic), 1701 (C=0). 1H NMR (DMSOd6): $87.21-7.76$ (m, 14H Ar$\mathrm{H}), 4.5\left(\mathrm{~s}, 2 \mathrm{H}, \mathrm{CH}_{2}\right.$ ), $4.4\left(\mathrm{~s}, 2 \mathrm{H}, \mathrm{CH}_{2}\right.$ ). 13C NMR (DMSO-d6): $\delta 174.06$, $166.42,136.30,133.67,132.35,129.50,129.04,128.95,128.73$, 36.82 , 46.35. Elemental analysis calculated for $\mathrm{C}_{23} \mathrm{H}_{18} \mathrm{O}_{3}(\%)$ Calcd. /found C, 80.68/8067; H, 5.30/531.

3 ,3'-(ethane-1,2-diylbis(azanediyl))bis(1-(naphthalen-2yloxy)propan-2-ol ) (6)

Yellowish powder in $59 \%$ yield, MP. $219-222^{\circ} \mathrm{C}$. IR (v) (KBr) $\mathrm{cm}^{-1}$ : $3341(\mathrm{OH}), 3325(\mathrm{NH}), 3033$ (C-H aromatic), 2922 (C-H aliphatic). $1 \mathrm{H}$ NMR (DMSO-d6): $\delta 7.12-7.81(\mathrm{~m}, 2 \mathrm{H}, 2 \mathrm{NH}$ and $14 \mathrm{H}$, $\mathrm{Ar}-\mathrm{H}$ ), 5.05 (s, 2H, 2OH), $4.12\left(\mathrm{~m}, 2 \mathrm{H}, 2 \mathrm{CH}\right.$ and $8 \mathrm{H}, 4 \mathrm{CH}_{2}$ ), $32.8(\mathrm{~s}$, $4 \mathrm{H}, 2 \mathrm{CH}_{2}$ ). 13C NMR (DMSO-d6): $\delta 157.20,133.90,128.06,126.90$, 124.15, 123.14, 119.29, 71.39, 57.22 31.73, 22.98. Elemental analysis calculated for $\mathrm{C}_{26} \mathrm{H}_{28} \mathrm{~N}_{2} \mathrm{O}_{4}(\%)$ : Calcd./found C, 73.02/73.01; H, 7.0/07.02; N, 6.08/6.06.

\section{1-(butylamino)-3-(naphthalen-2-yloxy) propan-2-ol (7)}

White powder in $88 \%$ yield, MP. $233-236{ }^{\circ} \mathrm{C}$. IR (v) $(\mathrm{KBr}) \mathrm{cm}^{-1}$ : 3496 (OH), 3024 (C-H aromatic), 2920, 2819 (C-H aliphatic). 1H NMR (DMSO): $\delta$ 7.12-7.71 (m, 1H, NH and 7H, Ar-H), $4.95(\mathrm{~s}, 1 \mathrm{H}$, $\mathrm{OH}), 4.12(\mathrm{~s}, 4 \mathrm{H}, \mathrm{CH}), 2.9(\mathrm{~s}, 1 \mathrm{H}, \mathrm{CH}), 4.82(\mathrm{~s}, 3 \mathrm{H}, \mathrm{CH}), 4.82(\mathrm{~s}, 1 \mathrm{H}$, $\mathrm{CH}$ ), 4.82 (s, 1H, CH), 4.82 (s, 3H, CH3). 13C NMR (DMSO-d6): $\delta$ 157.20, 134.70, 129.94, 1.28.96, 127.89, 127.05, 126.69, 123.89, $119.15,107.2,71.17,67.86,58.64,55.78,29.50,20.54,14.25$. DEPT 135 (DMSO-d6): $\delta 129.56(\mathrm{CH}), 127.90(\mathrm{CH}), 127.06(\mathrm{CH}), 126.7$ $(\mathrm{CH}), 123.90(\mathrm{CH}), 119.18(\mathrm{CH}), 107.14(\mathrm{CH}), 106.9(\mathrm{CH}), 71.17$ $(\mathrm{CH}), 70.97(\mathrm{OCH}), 14.33\left(\mathrm{OCH}_{2}\right)$. Elemental analysis calculated for $\mathrm{C}_{17} \mathrm{H}_{21} \mathrm{NO}_{2}$ (\%) Calcd. /found C, 74.69/74.77; H, 8.48/8.47; N, 5.12/5.13.

\section{1-(hexylamino)-3-(naphthalen-2-yloxy) propan-2-ol (8)}

Pale white powder $73 \%$ yield, MP. $123-126{ }^{\circ} \mathrm{C}$. IR (v) (KBr) $\mathrm{cm}^{-1}$ : 3313 (OH), 3024 (C-H aromatic), 3055, 3029 (C-H aromatic), 2920 (C-H aliphatic). 1H NMR (DMSO-d6): $\delta$ 7.12-7.81 (m, 7H, $7 \mathrm{H}, \mathrm{Ar}-\mathrm{H}), 4.25$ (s, 1H, OH), $4.12(\mathrm{~s}, 2 \mathrm{H}, \mathrm{CH}), 2.8(\mathrm{~s}, 1 \mathrm{H}, \mathrm{CH}), 2.7$ (s, 1H, CH), $2.6(\mathrm{~s}, 2 \mathrm{H}, \mathrm{CH}), 1.44(\mathrm{~s}, 2 \mathrm{H}, \mathrm{CH}), 1.42(\mathrm{~s}, 6 \mathrm{H}, \mathrm{CH}), 1.2(\mathrm{~s}$, 3H, CH3). 13C NMR(DMSO-d6,): $\delta 157.14,134.80,129.66,1.28 .96$, $127.92,127.11,126.75,123.92,119.21,107.26,71.39,68.55$, $52.97,49.96,31.73,29.98,26.92,22.55,14.33$. Elemental analysis calculated for $\mathrm{C}_{19} \mathrm{H}_{25} \mathrm{NO}_{2}$ (\%) Calcd. /found C, 75.71/75.70; $\mathrm{H}$, 9.03/9.05; N, 4.65/4.63. 
3,3'-(hydrazine-1,2-diyl) bis(1-(naphthalen-2-yloxy) propan2-ol) (9)

Yellowish powder in $59 \%$ yield, MP. $219-222^{\circ} \mathrm{C}$. IR (v) (KBr) $\mathrm{cm}^{-1}$ : 3340, 3323 (OH, NH), 3039 (C-H aromatic), 2924 (C-H aliphatic). 1H NMR (DMSO-d6): $\delta 9.71(\mathrm{~s}, 2 \mathrm{H}, 2 \mathrm{NH}), 7.18-7.81(\mathrm{~m}$, $28 \mathrm{H}, \mathrm{Ar}-\mathrm{H}), 5.11(\mathrm{~s}, 2 \mathrm{H}, 2 \mathrm{OH}), 4.51(\mathrm{~m}, 2 \mathrm{H}, 2 \mathrm{CH}), 4.15(\mathrm{~m}, 8 \mathrm{H}, 4 \mathrm{CH} 2)$. 13C NMR (DMSO-d6): $\delta 157.11,134.78,129.69,127.93,126.78$, $123.96,107.28,71.36,68.80,53.25$. Elemental analysis calculated for $\mathrm{C}_{26} \mathrm{H}_{28} \mathrm{~N}_{2} \mathrm{O}_{4}$ (\%) Calcd. /found C, 72.20/72.18; H, 6.53/6.52; N, 6.48/6.49.

1-cyclopropyl-6-fluoro-7-(4-(2-hydroxy-3-(naphthalen-2yloxy)propyl)piperazin-1yl)-4-oxo-1,4- dihydroquinoline-3carboxylic acid(10)

Pal white powder in $70 \%$ yield, MP. $210-212^{\circ} \mathrm{C}$. IR (v) (KBr)cm ${ }^{1}: 3344(\mathrm{OH}), 3018$ (C-H aromatic), 2957, 2863C-H aliphatic), 1726 $(\mathrm{C}=0)$ ). 1H NMR (DMSO-d6): $\delta 14.60(\mathrm{OH}), 8.46(\mathrm{NH}), 7.12-7.71$ (m, 10H, Ar-H), 4.95 (s, 1H, OH), 4.12-3.81 (m, 5H, CH), 2.6 (d, 8H, CH2), 1.12 (m, 5H, CH). 13C NMR (DMSO-d6)): $\delta$ 157.20, 134.70, $129.94,1.28 .96,127.89,127.05,126.69,123.89,119.15,107.2$, 71.17, 67.86, 58.64, 55.78, 29.50, 20.54, 14.25. Elemental analysis calculated for $\mathrm{C}_{30} \mathrm{H}_{30} \mathrm{FN}_{3} \mathrm{O}_{5}$ (\%) Calcd. /found C, 67.78/67.76; $\mathrm{H}$, 5.69/5.68; N, 7.90/7.91.

\section{3,3',3"'-nitrilotris(1-(naphthalen-2-yloxy) propan-2-ol) (11)}

Pale White powder in $92 \%$ yield, MP. $138-140{ }^{\circ} \mathrm{C}$. IR (v) (KBr) $\mathrm{cm}^{-1}: 3221$ (OH), 2919, 2813 (C-H aliphatic). 1H NMR (DMSO-d6): $\delta$ 7.12-7.81 (m, 21H, Ar-H), $5.04(\mathrm{~s}, 3 \mathrm{H}, \mathrm{OH}), 4.12\left(\mathrm{~m}, 6 \mathrm{H}, \mathrm{CH}_{2}\right.$ and $3 \mathrm{H}, \mathrm{CH}$ ), 2.9 (m, 6H, $\mathrm{CH}_{2}$ ).13C NMR (DMSO-d6): $\delta$ 157.11, 134.78, 129.70, 127.94, 123.97, 119.23, 107.28, 73.02, 69.80, and 53.2. Elemental analysis calculated for $\mathrm{C}_{39} \mathrm{H}_{39} \mathrm{NO}_{6}$ (\%) Calcd. /found; C, 75.83/75.82; H, 6.36/6.35; N, 2.27/2.28.

\section{Laboratory Bioassay}

The insecticidal bio-efficacy of all prepared Epihalohydrins analogues was assessed by the leaf dipping bioassay procedure. Research facility of tested results are accounted here for the used compounds to discover the appropriate concentration that are required to kill half $50 \%$ (LC50) of the pests. In this search, five concentrations of each synthesized naphthalene derivatives and $0.1 \%$ Triton X-100 as surfactant were utilized. A number total of 10 larvae of spodoptera littoralis (Boisd.), almost of the 2nd instar larvae and 4 th instar larvae size, Disks $(9 \mathrm{~cm}$. diameter) of castor bean leaves were dipped in the tested concentrations for 10 seconds then left to dry and offered to larvae. Larvae were placed into glass jars ( 5 pounds), every treatment was recreated multiple times (10 larvae per each). Control disks were dunked in distilled water only. In which allowed the larvae to feed on castor bean leaves for $48 \mathrm{hr}$ [18]. then transferred to the untreated ones. Mortality percentages were recorded after $72 \mathrm{hr}$. for all insecticides. Mortality was redressed by Abbott's formula [19]. The measurements mortality relapse lines were measurably dissected by probit analysis [20]. Harmfulness Index was determined by sun equations [21].

\section{Insecticidal Bio-efficacy Examination}

Table 1: Insecticidal activity of Compounds $1-11$ and Fenoxycarb against the $2^{\text {nd }}$ larvae of spodoptera littoralis (Boisd.), after $72 \mathrm{~h}$ of Treatment.

\begin{tabular}{|c|c|c|c|}
\hline \multirow{2}{*}{ Compound Fenoxycarb } & $\mathbf{L C}_{\mathbf{5 0}} \mathbf{( \mathbf { p p m } )}$ & $\mathbf{S l o p e} \pm$ SE & Toxic Ratio $^{\mathbf{a}}$ \\
\hline 1 & 25.04 & $\mathbf{0 . 2 3 8} \pm$ SE & 0.109 \\
\hline 2 & 17.56 & $0.283 \pm 0.083$ & 0.155 \\
\hline 3 & 15.64 & $0.238 \pm 0.076$ & 0.174 \\
\hline 4 & 38.69 & $0.299 \pm 0.083$ & 0.07 \\
\hline 5 & 34.68 & $0.256 \pm 0.082$ & 0.078 \\
\hline 6 & 6.07 & $0.272 \pm 0.083$ & 0.449 \\
\hline 7 & 44.08 & $0.262 \pm 0.079$ & 0.0619 \\
\hline 9 & 42.05 & $0.279 \pm 0.084$ & 0.0651 \\
\hline 10 & 10.06 & $0.293 \pm 0.0862$ & 0.275 \\
\hline
\end{tabular}

aThe ratio of the $\mathrm{LC}_{50}$ values of fenoxycarb for baseline toxicity and the compounds are defined as a toxic ratio.

The compounds which prepared have been tested for their insecticidal bio-efficacy, demonstrated as follows: compounds from 1-11 were tested against the 2 nd instar larvae for their activity as insecticidal, and the outcomes are introduced in Table 1 . After $72 \mathrm{~h}$ of treatment, activity results demonstrated that these compounds show high to low insecticidal activity against the 2nd instar larvae and the LC50 regards stretched out from 3.71 to $44.08 \mathrm{ppm}$, however the LC50 estimation of fenoxycarb was $2.37 \mathrm{ppm}$. This shows that nearly insecticidal bio-efficacy of fenoxycarb as insect growth regulators after $72 \mathrm{~h}$ of test. In which compounds 6,10 and 11 have 
generally excellent insecticidal bio-efficacy against 2nd because that their LC50 esteems were 6.07, 4.80 and 3.710, respectively, in which the LC50 estimation value of fenoxycarb was $2.37 \mathrm{ppm}$.

The results of insecticidal bio-efficacy after $72 \mathrm{~h}$ for compounds 1-11 were tested against the 4th instar larvae shown in Table 2. Varied from strong to weak with LC50 values assorted from 50.60 to $103.01 \mathrm{ppm}$, while the LC50 value of fenoxycarb was $42.231 \mathrm{ppm}$. In which demonstrates that various them have tested compound near that of fenoxycarb as juvenile hormone after $72 \mathrm{~h}$ of test. For instance, compounds 6, 10 and 11 have generally excellent insecticidal exercises activities against 4th instar larvae because their LC50 values were 54.631, 57.622 and 50.606, respectively, and the LC50 value of fenoxycarb was $43.231 \mathrm{ppm}$.

Table 2: Insecticidal activity of compounds 1-11and Fenoxycarb against the 4th larvae of spodoptera littoralis (Boisd.), after $72 \mathrm{~h}$ of Treatment.

\begin{tabular}{|c|c|c|c|}
\hline Compound Fenoxycarb & LC $_{\mathbf{5 0}}$ (ppm) $\mathbf{4 3 . 2 3 1}$ & $\begin{array}{c}\text { Slope } \pm \text { SE } \\
\mathbf{0 . 2 5 1 \pm 0 . 0 8 2 0}\end{array}$ & $\begin{array}{c}\text { Toxic ratio }^{\mathbf{a}} \\
\mathbf{1}\end{array}$ \\
\hline 1 & 72.253 & $0.232 \pm 0.0856$ & 0.598 \\
\hline 2 & 69.252 & $0.255 \pm 0.0862$ & 0.624 \\
\hline 3 & 80.352 & $0.220 \pm 0.0811$ & 0.538 \\
\hline 4 & 86.921 & $0.231 \pm 0.0823$ & 0.497 \\
\hline 5 & 97.371 & $0.229 \pm 0.0813$ & 0.791 \\
\hline 6 & 54.631 & $0.189 \pm 0.0775$ & 0.419 \\
\hline 9 & 103.01 & $0.234 \pm 0.0830$ & 0.497 \\
\hline 10 & 86.98 & $0.231 \pm 0.0823$ & 0.693 \\
\hline 11 & 62.352 & $0.252 \pm 0.0821$ & 0.75 \\
\hline
\end{tabular}

\section{Structure Framework Relationship}

It shows up from the general search structure of the prepared naphthalene derivatives compounds of 11 and 10are more active against 2 nd instar larvae and 4th instar larvae than the another's of tested compounds. It additionally demonstrated that exacerbates that contain an exceptionally ether group in the structure claim a high insecticidal bio-efficacy. Thus, compounds $6,9,10$, and 11 more active than compounds 1, 2, 3, 4, 7 and 8 in-insecticidal bioefficacy.

\section{References}

1. Marwa FK, Ali AM (2017) Impact of some essential plant oils and insect growth regulators on immature stages of spodoptera littoralis (Boisd.). Lepidoptera: Noctuidae 8(11): 561-570

2. Amira SMI (2019) Sterilizing activity of the insect growth regulator, lufenuron on drosohpila melanogaster (Meigen). J Plant Prot and Path 10(5): 297-302.

3. GelbicI, Adel MM, Hussein HM (2011) Effects of nonsteroidal ecdysone agonist RH-5992 and chitin biosynthesis inhibitor lufenuron on Spodoptera littoralis (Boisduval, 1833). Central European Journal of Biology 6: 861-869.

4. Nasr HM, Badawy MEI, Rabea EI (2010) Toxicity and biochemical study of two insect growth regulators, buprofezin and pyriproxyfen, on cotton leafworm Spodoptera littoralis. Pestic Biochem Physiol 98(2): 198-205.

5. Wheeler DE, Nijhout HF (2003) A perspective for understanding the modes of juvenile hormone action as a lipid signaling system. Bio Essays 25(10): 994-1001.

6. Niu JJ, Meng Q, Chai HY, Chu KH, et al. (2019) Effects of two juvenile hormone analogue insecticides, fenoxycarb and methoprene on neocaridina davidi. Environmental Pollution 253: 89-99.
7. El Sheikh EA, Kamita SG, Vu K, Hammock BD (2011) Improved insecticidal efficacy of a recombinant baculovirus expressing mutated JH esterase from Manduca sexta. Biol Control 58(3): 354-361.

8. Bortolotti L, Porrini C, Sbrenna AM, Sbrenna G (2000) Ovicidal action of fenoxycarb on a predator, Chrysoperla carnea. Appl Entomol Zool 35(2): 265-270.

9. Khalil SMS, Anspaugh DD, Roe RM (2006) Role of juvenile hormone esterase and epoxide hydrolase in reproduction of the cotton bollworm helicoverpa zea. J Insect Physiol 52(7): 669-678.

10. Wilson TG (2004) The molecular site of action of juvenile hormone and juvenile hormone insecticides during metamorphosis: how these compounds kill insects. J Insect Physiol 50(2-3): 111-121.

11. Retnakaran A, Granett J, Ennis T (1985) Ennis Insect growth regulators. In: Kerkut G, Gilbert LI (Eds.), Comprehensive Insect Physiology, Biochemistry and Pharmacology 12, Pergamon Press, New York, USA, pp. 529-601.

12. Dedos SG, Szurduki F, Skarlatos Székácsc A, Shiotsuki T, Hammock BD, et al. (2002) Fenoxycarb levels and their effects on general and juvenile hormone esterase activity in the hemolymph of the silkworm, bombyx mori. Pesticide Biochemistry and Physiology 73(3): 174-187.

13. Staal GB (1975) Insect growth regulators with juvenile hormone activity. Annu Rev Entomol 20: 417-460.

14. Wael LD, Greef MD, Laere OV (1995) Toxicity of pyriproxifen and fenoxycarb to bumble bee brood using a new method for testing insect growth regulators. J Apicultural Research. 34(1): 3-8.

15. Riddiford LM (2008) Juvenile hormone action: a 2007 perspective. J Insect Physiol 54(6): 895-901.

16. Zera JA, Tanaka S (1996) The role of juvenile hormone and juvenile hormone esterase in wing morph determination in Modicogryllus confirmatus. J Insect Physiology. 42(9): 909-915. 
17. Abdel-Aal YAI, Hammock BD (1986) Transition state analogs as ligands for affinity purification of juvenile hormone esterase. Science 233(4768): 1073-1076.

18. Kamita SG, Hammock BD (2010) Juvenile hormone esterase: biochemistry and structure. J Pestic Sci 35(3):265-274.

19. Abbott WS (1987) A method of computing the effectiveness of an insecticide. J Econ Entomol. 18:265-267.
20. Finney DJ (1952) Probit analysis a statistical treatment of the sigmoid response curve, cambridge university press. Cambridge, USA 116 (3011): 286-287

21. Sun YP (1950) Toxicity index-An Improved method of comparing the relative toxicity of insecticides. J Econ Entomol 43 (1): 45-53.

For possible submissions Click below: 